\title{
Solvent Effect on Radical Polymerization of Methyl Methacrylate
}

\author{
Mikiharu KamaCHI, Der Jang LIAw, and Shun-ichi NozaKuRA \\ Department of Macromolecular Science, Faculty of Science, Osaka University, \\ 1-1, Machikaneyama, Toyonaka, Osaka 560, Japan.
}

(Received April 23, 1980)

\begin{abstract}
The radical polymerization of methyl methacrylate (MMA) in various aromatic solvents was studied under the same conditions as that of phenyl methacrylate (PMA) reported previously. The propagation-rate constants $\left(k_{\mathrm{p}}\right)$ and termination-rate constants $\left(k_{\mathrm{t}}\right)$ were determined by intermittent illumination methods. The variation in the $k_{\mathrm{p}}$ values for MMA with aromatic solvents had the same trend as that for PMA, although the solvent effect on the former values was somewhat smaller than that on the latter. Variation in $k_{\mathrm{p}}$ values with solvents can be explained by the formation of an electron donor-acceptor complex and is correlated with the delocalization stabilization of the complex formation. The dependence of $k_{\mathrm{p}}$ value on the monomer concentration supports the view that a propagating radical complexed with a solvent is in the dormant state. A study of temperature dependence on $k_{\mathrm{p}}$ and $k_{\mathrm{t}}$ values was also carried out in benzene and activation energy of these values determined to be $5.0 \pm 0.8$ and $0.38 \pm 0.10 \mathrm{kcal} \mathrm{mol}^{-1}$, respectively.
\end{abstract}

KEY WORDS Methyl Methacrylate / Radical Polymerization / Polymerization Rate / Elementary Rate Constant / Initiation Rate / Solvent Effect / Delocalization Stabilization /

We previously reported that the trend in aromatic solvent effect on the polymerization-rate constant of phenyl methacrylate (PMA) $(e=0.73)$ is opposite to that observed for vinyl benzoate $(e=-0.55) .{ }^{1-3}$ This opposite effect is explained in terms of a donor-acceptor complex formation between the propagating radical and the $\pi$-system of the solvents.

If a complex formation occurs, the same solvent effect will be observed on the rate constant in the polymerization of methyl methacrylate (MMA), since the nature of the propagating radical of MMA is similar to that of PMA. Although Bamford et al., ${ }^{4,5}$ Burnett et al., ${ }^{6}$ and Yamamoto et al. ${ }^{7}$ have independently measured the rate constants in the polymerization of MMA in aromatic solvents, the experimental conditions in each case were different from that for $\mathrm{PMA}^{1,2}$ with respect to monomer concentrations and temperature. In order to compare the aromatic-solvent effect on the polymerization of MMA with that of PMA, results obtained under the same conditions must be used, since different laboratories frequently show different values for the rate constant even for the same

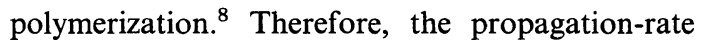
constant for the radical polymerization of MMA in aromatic solvents was determined under the same conditions as that for PMA. ${ }^{1,2}$

In this paper, we report the results of the determination of rate constants for MMA in various aromatic solvents and discuss the cause for the solvent participation in the polymerization. In addition, we mention the monomer concentration and the temperature dependence on $k_{\mathrm{p}}$ for MMA in benzene.

\section{EXPERIMENTAL}

MMA, aromatic solvents, 2,2'-azobisisobutyronitrile (AIBN), 2,2'-azobiscyclohexanecarbonitrile) (ACN), and 1,1'-diphenyl-2-picrylhydrazyl (DPPH) were purified as previously described. ${ }^{2}$

The rate of polymerization $\left(R_{\mathrm{p}}\right)$, the rate of initiation $\left(R_{\mathrm{j}}\right)$, and radical lifetime $(\tau)$ were de- 
termined as described in a previous paper. $^{2}$ Monomer and initiator concentrations were completely the same as described in the PMA polymerization. $^{2}$

Experimental error for the rate constants was estimated in the same method as previously described. $^{2}$

The intrinsic viscosity of the polymer was determined in benzene at $30^{\circ} \mathrm{C}$ with an Ostwald viscometer.

A Varian A-60 nuclear magnetic resonance (NMR) spectrometer was used with tetramethylsilane as the internal reference ( $5 \%$ solution).

A Neac-2200 computer was used for making the calculations involved in the LCAO MO method.

\section{RESULTS}

Determination of $k_{\mathrm{p}}$ and $k_{\mathrm{t}}$

The rate dependence on initiator and monomer concentration was determined at $30 \pm 0.001^{\circ} \mathrm{C}$ for both the initiator and photosensitized polymerization. Typical examples of the results obtained in benzene are shown in Figures 1 and 2. Also, it was confirmed with other solvents that the rates of polymerization were proportional to the monomer concentration and to the square root of the initiator concentration. These results suggest that degradative chain transfers or unimolecular terminations are not important in the polymerization.

In order to determine the elementary rate constants, the initiation rates $\left(R_{\mathrm{i}}\right)$ were determined by the inhibition method using DPPH as an
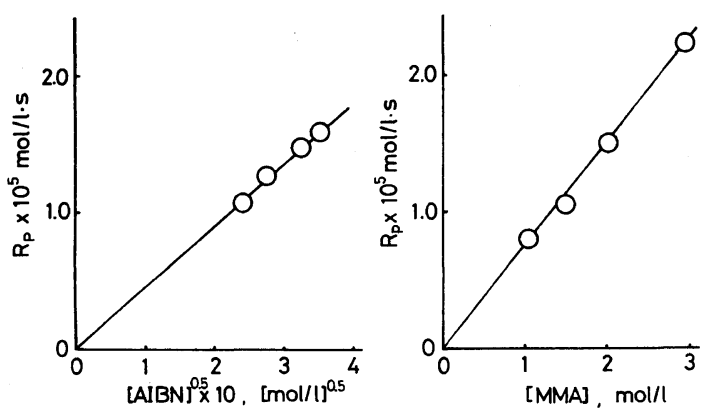

Figure 1. Dependence of the polymerization rate on monomer and initiator concentrations in thermal initiated polymerization at $30^{\circ} \mathrm{C}$; solvent, benzene; (a), [monomer], $2.00 \mathrm{~mol} \mathrm{l}^{-1}$; (b), [2,2'-azobisisobutyronitrile], $0.1 \mathrm{~mol} \mathrm{l}^{-1}$. inhibitor in all solvents. The effect of the addition of DPPH on the initiated polymerization and the correlation between the obtained duration of inhibition and the concentration of the inhibitor in benzene are shown in Figures 3 and 4. Similar
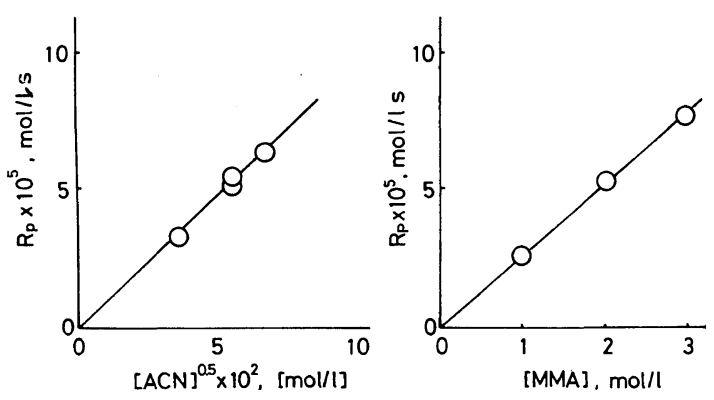

Figure 2. Dependence of the polymerization rate on monomer and initiator concentrations in photosensitized polymerization at $30^{\circ} \mathrm{C}$; solvent, benzene; (a), [monomer], $2.00 \mathrm{~mol} \mathrm{1}^{-1}$; (b), [2,2'-azobiscyclohexanecarbonitrile], $3.0 \times 10^{-3} \mathrm{~mol}^{-1}$.

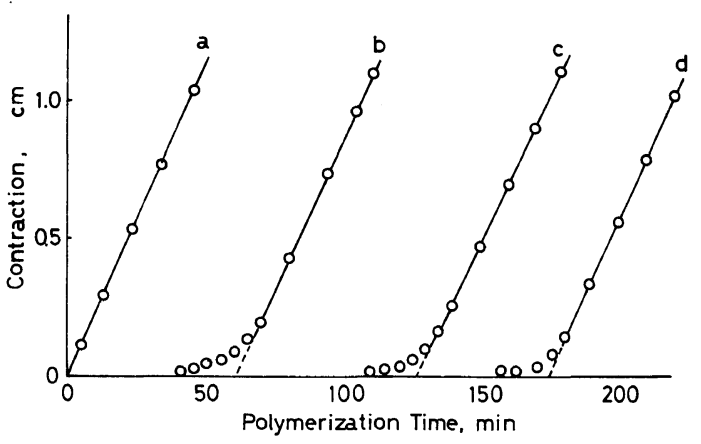

Figure 3. Inhibition effect of DPPH in the polymerization of methyl methacrylate in benzene at $30^{\circ} \mathrm{C}$; [methyl methacrylate], $2.00 \mathrm{~mol} \mathrm{1}^{-1} ;\left[2,2^{\prime}\right.$-azobisisobutyronitrile], $0.1 \mathrm{~mol} \mathrm{1}^{-1}$; [DPPH]: a, 0; b, 0.456; c, 0.798; d, $1.14 \times 10^{-4} \mathrm{moll}^{-1}$.

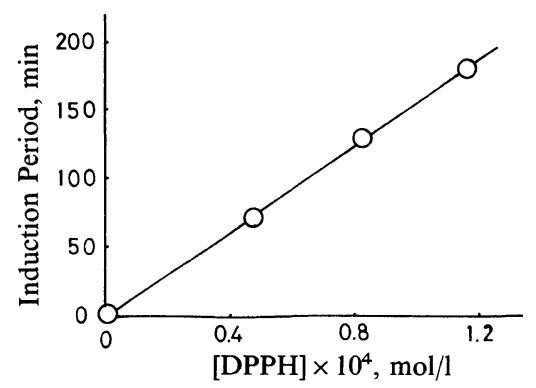

Figure 4. Relationship between inhibitor concentration and induction period. 
Table I. Initiator polymerization rate and initiation rate in various solvents at $30^{\circ} \mathrm{C}$

\begin{tabular}{|c|c|c|c|}
\hline \multirow{2}{*}{ Solvents } & $R_{\mathrm{p}} \times 10^{5 \mathrm{a}}$ & $R_{\mathrm{i}} \times 10^{8 \mathrm{a}, \mathrm{b}}$ & $\left(k_{\mathrm{p}}^{2} / k_{\mathrm{t}}\right) \times 10^{3}$ \\
\hline & $\mathrm{moll}^{-1} \mathrm{~s}^{-1}$ & $\mathrm{~mol} \mathrm{l}^{-1} \mathrm{~s}^{-1}$ & $\mathrm{~mol} \mathrm{l}^{-1} \mathrm{~s}^{-1}$ \\
\hline (O) $-\mathrm{OCH}_{3}$ & $1.77 \pm 0.09(3)^{\mathrm{c}}$ & $1.09 \pm 0.07(3)^{\mathrm{c}}$ & 71.19 \\
\hline (0) & $1.45 \pm 0.08$ & $1.09 \pm 0.04$ & 4.82 \\
\hline (0) $-F$ & $1.40 \pm 0.08$ & $1.15 \pm 0.05$ & 4.26 \\
\hline (O) $-\mathrm{Cl}$ & $1.58 \pm 0.05$ & $1.08 \pm 0.05$ & 5.78 \\
\hline (O) $-\mathrm{CN}$ & $2.03 \pm 0.07$ & $1.09 \pm 0.06$ & 9.45 \\
\hline
\end{tabular}

a $[\mathrm{AIBN}], 0.10 \mathrm{~mol} \mathrm{1}^{-1}$; [monomer], $2.00 \mathrm{~mol} \mathrm{l}^{-1}$.

b Inhibitor, DPPH.

c Run number.

behavior was observed in initiator polymerizations using other solvents.

$R_{\mathrm{i}}$ can be calculated from Figure 4, the values of $k_{\mathrm{p}}^{2} / k_{\mathrm{t}}$ being derived from $R_{\mathrm{i}}$ and the rate of initiator polymerization. These results are shown in Table I.

The mean lifetime of the propagating radical was determined by the rotating sector method at $30 \pm 0.001{ }^{\circ} \mathrm{C}$. Figure 5 shows the variation in the rate of polymerization with illumination time. The mean lifetime of the growing chain was determined to be $0.47 \mathrm{~s}$. In Table II, the rate of the photosensitized polymerization, the lifetime, and derived values of $k_{\mathrm{p}} / k_{\mathrm{t}}$ are shown together with $k_{\mathrm{p}}$ and $k_{\mathrm{t}}$, obtained by combining the values of $k_{\mathrm{p}} / k_{\mathrm{t}}$ and $k_{\mathrm{p}}^{2} / k_{\mathrm{t}}$. Since the number of the measurements of the $k_{\mathrm{p}}$ and $k_{\mathrm{t}}$ values was too few to permit estimation of the standard deviation, the relative precision of these values was estimated by the amount of deviation from the mean in three or four runs, that of the $k_{\mathrm{p}}$

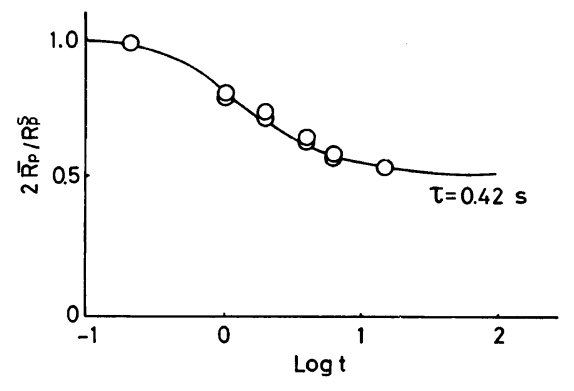

Figure 5. Determination of the average life-time of propagating radicals from methyl methacrylate in benzene at $30^{\circ} \mathrm{C}: \bar{R}_{\mathrm{p}}$, rate of overall polymerization at intermittent illumination; $R_{\mathrm{p}}^{\mathrm{s}}$, rate at stationary state under continuous irradiation; $t$, intermittent illumination time (s), ratio of dark to light $=3$; [2,2'-azobiscyclohexanecarbonitrile], $3.00 \times 10^{-3} \mathrm{moll}^{-1}$; [methyl methacrylate], $2.00 \mathrm{moll}^{-1}$.

Table II. Rate constants in various solvents at $30^{\circ} \mathrm{C}$

\begin{tabular}{|c|c|c|c|c|c|}
\hline \multirow{2}{*}{ Solvents } & $R_{\mathrm{p}} \times 10^{5 \mathrm{a}}$ & $\tau$ & \multirow{2}{*}{$\left(k_{\mathrm{p}} / k_{\mathrm{t}}\right) \times 10^{5}$} & $k_{\mathrm{p}}$ & \multirow{2}{*}{$\frac{k_{\mathrm{t}} \times 10^{-7}}{\operatorname{mol~} 1^{-1} \mathrm{~s}^{-1}}$} \\
\hline & $\mathrm{mol} \mathrm{1} 1^{-1} \mathrm{~s}^{-1}$ & $\mathrm{~s}$ & & $\mathrm{~mol} \mathrm{l}^{-1} \mathrm{~s}^{-1}$ & \\
\hline (O) $-\mathrm{OCH}_{3}$ & $6.16 \pm 0.10(3)^{b}$ & $0.46 \pm 0.04(3)^{b}$ & $1.42^{\mathrm{c}}$ & $506 \pm 48(3)^{b}$ & $3.56 \pm 0.39(3)^{b}$ \\
\hline (0) & $5.11 \pm 0.12$ & $0.42 \pm 0.03(4)$ & 1.07 & $450 \pm 33(4)$ & $4.20 \pm 0.30$ \\
\hline (0) $-\mathrm{F}$ & $4.67 \pm 0.10$ & $0.41 \pm 0.05$ & 0.95 & $448 \pm 47$ & $4.72 \pm 0.66$ \\
\hline (O) $-\mathrm{Cl}$ & $5.42 \pm 0.09$ & $0.43 \pm 0.04$ & 1.16 & $498 \pm 39(3)$ & $4.29 \pm 0.47$ \\
\hline (O) $-\mathrm{CN}$ & $6.87 \pm 0.13$ & $0.45 \pm 0.03$ & 1.54 & $614 \pm 43$ & $3.99 \pm 0.33$ \\
\hline $\mathrm{C}_{6} \mathrm{D}_{6}$ & $5.20 \pm 0.09(2)$ & $0.40 \pm 0.03(2)$ & 1.04 & $456 \pm 29$ & $4.38 \pm 0.20(2)$ \\
\hline
\end{tabular}

a $\left[2,2^{\prime}\right.$-Azobis(cyclohexanecarbonitrile)], $3.00 \times 10^{-3} \mathrm{~mol} \mathrm{l}^{-1}$; [Monomer], $2.00 \mathrm{~mol} \mathrm{l}^{-1}$.

b Run number.

c Mean value. 
values being less than $10 \%$ and that of the $k_{\mathrm{t}}$ values less than $15 \%$. Limits for the error in $k_{\mathrm{p}}$ and $k_{\mathrm{t}}$ were estimated by the following formula in which all deviations of individual measurements were taken into account:

$$
\begin{aligned}
& \left|\frac{\Delta k_{\mathrm{p}}}{k_{\mathrm{p}}}\right|=\left|\frac{\Delta R_{\mathrm{p}}}{R_{\mathrm{p}}}\right|+\left|\frac{\Delta R_{\mathrm{i}}}{R_{\mathrm{i}}}\right|+\left|\frac{\Delta \tau}{\tau}\right|+\left|\frac{\Delta W_{\mathrm{m}}}{W_{\mathrm{m}}}\right|+\left|\frac{\Delta W_{\mathrm{c}}}{W_{\mathrm{c}}}\right| \\
& \left|\frac{\Delta k_{\mathrm{t}}}{k_{\mathrm{t}}}\right|=\left|\frac{\Delta R_{\mathrm{i}}}{R_{\mathrm{i}}}\right|+2\left|\frac{\Delta \tau}{\tau}\right|+\left|\frac{\Delta W_{\mathrm{c}}}{W_{\mathrm{c}}}\right|
\end{aligned}
$$

where $W_{\mathrm{m}}$ and $W_{\mathrm{c}}$ are weights of monomer and initiator, respectively. The limits for error of $k_{\mathrm{p}}$ and $k_{\mathrm{t}}$ were estimated to be around $12 \%$ and $20 \%$, respectively. Accordingly, the variation in $k_{\mathrm{p}}$ with solvents is beyond the limit of error, indicating that there is indeed a solvent effect on the propagating process.

The termination-rate constants were approximately correlated with the reciprocal viscosities of the polymerization system, as shown in Figure 6. The viscosities of the polymerization system were calculated from the viscosities of the constituents, assuming a linear relation of viscosity to the volume composition.

The monomer-concentration dependence and the temperature dependence of $k_{\mathrm{p}}$ were determined in

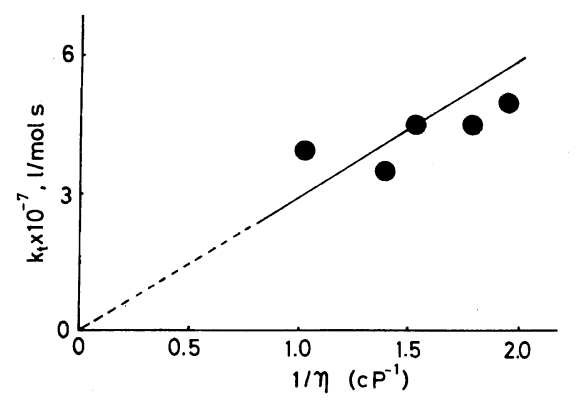

Figure 6. Correlation of $k_{\mathrm{t}}$ values with viscosity of polymerization systems.

\begin{tabular}{|c|c|c|c|c|c|c|}
\hline \multirow{2}{*}{ Monomer concn. } & $R_{\mathrm{p}} \times 10^{5 \mathrm{a}}$ & $R_{\mathrm{i}} \times 10^{8 \mathrm{a}, \mathrm{b}}$ & $k_{\mathrm{p}}^{2} / k_{\mathrm{t}} \times 10^{3}$ & \multirow{2}{*}{$k_{\mathrm{p}} / k_{\mathrm{t}} \times 10^{5 \mathrm{c}}$} & \multirow{2}{*}{$\frac{k_{\mathrm{p}}}{\mathrm{mol} \mathrm{1}^{-1} \mathrm{~s}^{-1}}$} & \multirow{2}{*}{$\frac{k_{\mathrm{t}} \times 10^{-7}}{\mathrm{~mol} 1^{-1} \mathrm{~s}^{-1}}$} \\
\hline & $\operatorname{mol~1} 1^{-1} \mathrm{~s}^{-1}$ & $\mathrm{~mol} \mathrm{1}^{-1} \mathrm{~s}^{-1}$ & $\operatorname{mol~} 1^{-1} \mathrm{~s}^{-1}$ & & & \\
\hline $1.0(10.0)^{\mathrm{d}}$ & $0.79 \pm 0.04(3)^{\mathrm{e}}$ & $1.06 \pm 0.03(3)^{\mathrm{e}}$ & $5.89^{\mathrm{f}}$ & $1.38^{\mathrm{f}}$ & $427 \pm 38(3)^{\mathrm{e}}$ & $3.09 \pm 0.37(3)^{\mathrm{e}}$ \\
\hline $2.0(8.81)$ & $1.45 \pm 0.08$ & $1.09 \pm 0.04(3)$ & 4.82 & 1.07 & $450 \pm 33(4)$ & $4.20 \pm 0.30(4)$ \\
\hline $3.0(7.62)$ & $2.29 \pm 0.09$ & $1.19 \pm 0.04$ & 4.90 & 1.08 & $454 \pm 36$ & $4.20 \pm 0.46(3)$ \\
\hline
\end{tabular}

Table III. Effect of the monomer concentration on rate constants in benzene at $30^{\circ} \mathrm{C}$

a $[\mathrm{AIBN}], 0.10 \mathrm{~mol} \mathrm{l}^{-1} ;$ [Monomer] $=2.00 \mathrm{~mol} \mathrm{1}^{-1}$.

b Inhibitor, DPPH.

c From rotating sector method.

d Solvent concentration.

e Run number.

f Estimation from mean values.

\begin{tabular}{|c|c|c|c|c|c|c|}
\hline Temp & $R_{\mathrm{p}} \times 10^{5 \mathrm{a}}$ & $R_{\mathrm{i}} \times 10^{8 \mathrm{a}, \mathrm{b}}$ & $k_{\mathrm{p}}^{2} / k^{\mathrm{t}} \times 10^{3}$ & $l_{1} \quad l_{1} \quad 10^{5}$ & $k_{\mathrm{p}}$ & $k_{\mathrm{t}} \times 10^{-7}$ \\
\hline${ }^{\circ} \mathrm{C}$ & $\operatorname{mol~1} 1^{-1} \mathrm{~s}^{-1}$ & $\operatorname{mol~1} 1^{-1} \mathrm{~s}^{-1}$ & $\operatorname{mol~1}^{-1} \mathrm{~s}^{-1}$ & & $\mathrm{~mol} \mathrm{1} \mathrm{l}^{-1} \mathrm{~s}^{-1}$ & $\mathrm{~mol} \mathrm{l}^{-1} \mathrm{~s}^{-1}$ \\
\hline 20 & $0.379 \pm 0.034(3)^{\mathrm{d}}$ & $0.160 \pm 0.008(3)^{\mathrm{d}}$ & $2.24^{\mathrm{e}}$ & $0.744^{e}$ & $301 \pm 36(3)^{d}$ & $4.05 \pm 0.54(3)^{d}$ \\
\hline 30 & $1.45 \pm 0.08$ & $1.09 \pm 0.04$ & 4.82 & 1.07 & $450 \pm 33(4)$ & $4.20 \pm 0.30(4)$ \\
\hline 40 & $4.28 \pm 0.29$ & $5.65 \pm 0.21$ & 8.11 & 1.36 & $596 \pm 71$ & $4.38 \pm 0.72$ \\
\hline
\end{tabular}

Table IV. Temperature dependence of rate constants in benzene

a [AIBN], $0.10 \mathrm{~mol} \mathrm{l}^{-1}$; [Monomer], $2.00 \mathrm{~mol} \mathrm{l}^{-1}$.

b Inhibitor, DPPH.

c From rotating sector method.

d Run number.

e Estimation from mean values. 
Table V. The chemical shift of olefinic proton for methacrylate monomers in various solvents ${ }^{\mathbf{a}, \mathbf{b}}$

\begin{tabular}{|c|c|c|c|c|c|c|}
\hline \multirow{3}{*}{ (O) $-X$} & \multicolumn{3}{|c|}{$\begin{array}{l}\text { Methyl methacrylate } \\
\mathrm{H}_{\mathrm{b} \backslash} \backslash \mathrm{C}=\mathrm{C} \backslash \mathrm{CH}_{3} \\
\mathrm{H}_{\mathrm{a}}{ }^{\backslash} \mathrm{COOCH}_{3}\end{array}$} & & $\mathrm{C}^{1 \text { metha }}$ & $\left.\mathrm{CH}_{3}\right)_{3}$ \\
\hline & $\delta \mathrm{H}_{\mathrm{a}}$ & $\delta \mathrm{H}_{\mathrm{b}}$ & $\Delta \delta \mathrm{H}^{\mathrm{c}}$ & $\delta \mathrm{H}_{\mathrm{a}}$ & $\delta \mathrm{H}_{\mathrm{b}}$ & $\Delta \delta \mathrm{H}^{\mathrm{c}}$ \\
\hline & $\mathrm{Hz}$ & $\mathrm{Hz}$ & $\mathrm{Hz}$ & $\mathrm{Hz}$ & $\mathrm{Hz}$ & $\mathrm{Hz}$ \\
\hline$-\mathrm{OCH}_{3}$ & 363.5 & 319.0 & 44.5 & 363.0 & 318.0 & 45.0 \\
\hline$-\mathrm{H}$ & 365.0 & 314.0 & 51.0 & 364.5 & 312.5 & 52.0 \\
\hline$-F$ & 364.5 & 321.0 & 43.5 & 364.5 & 320.0 & 44.5 \\
\hline$-\mathrm{Cl}$ & 363.0 & 320.5 & 42.5 & 363.0 & 319.2 & 43.8 \\
\hline$-\mathrm{Br}$ & 363.5 & 321.5 & 42.0 & 363.0 & 320.0 & 43.0 \\
\hline$-\mathrm{CN}$ & 365.0 & 331.0 & 34.0 & 364.0 & 328.7 & 35.3 \\
\hline
\end{tabular}

a Tetramethylsilane was used as an internal reference.

b In $5 \%$ solution.

c Data of reference 2.

benzene and are shown in Tables III and IV. Table III suggests that $k_{\mathrm{p}}$ is likely to decrease with an increase in the solvent concentration. From the Arrehnius plot of $k_{\mathrm{p}}$ and $\mathrm{k}_{\mathrm{t}}$ the activation energies were calculated to be $5.0 \pm 0.8$ and $0.38 \pm 0.10 \mathrm{kcal}$ $\mathrm{mol}^{-1}$.

\section{The Interaction of Monomer with Solvents}

The interaction between monomer and solvent was estimated by the difference in chemical shifts $(\Delta \delta)$ of $\beta$-olefinic protons of MMA. ${ }^{9,10}$ The results are shown in Table $\mathrm{V}$ along with data of $t$-butyl methacrylate ( $t$-BMA). Since the mean deviation of the difference was less than $1 \mathrm{~Hz}$, the observed difference is far beyond the experimental error, indicating that there is some interaction between monomer and solvent. Since the solvent dependence of the chemical shift of MMA was almost the same as that of $t$-BMA having bulky ester groups, the interaction between the carbonyl or alkoxy group and the solvent molecule does not seem important. The chemical shift of the olefinic proton in the cis position from ester group was scarecely influenced by the ratio of benzene to cyclohexane, but the chemical shift of the trans olefinic proton goes down field as the ratio increases (Table VI). This result shows that the trans olefinic proton $\left(\mathrm{H}_{b}\right)$ interacts with an aromatic ring. In order to estimate the extent of this interaction, NMR spectra were taken
Table VI. The chemical shift of the trans olefinic proton $\left(\mathrm{H}_{\mathrm{b}}\right)$ of methyl methacrylate at various concentration of benzen $e^{a, b}$

\begin{tabular}{cccccc}
\hline \multirow{2}{*}{ Solvent } & [Benzene] & & $\mathrm{H}_{\mathrm{b}}$ & & $\Delta^{\mathrm{c}}$ \\
\cline { 2 - 2 } \cline { 5 - 5 } \cline { 5 - 6 } & $\mathrm{mol} \mathrm{1}{ }^{-1}$ & & $\mathrm{~Hz}$ & & $\mathrm{~Hz}$ \\
\hline Cyclohexane & 0 & & 324 & \\
Benzene $50 \%$ & 5.56 & & 316 & & 8 \\
Benzene $70 \%$ & 7.68 & & 314 & & 10 \\
Benzene $90 \%$ & 9.92 & & 312 & & 12 \\
\hline
\end{tabular}

a [MMA], $9.0 \times 10^{-2} \mathrm{~mol} \mathrm{l}^{-1}$.

b Cyclohexane used as internal reference.

c $\Delta=\mathrm{H}_{\mathrm{b}}$ (Cyclohexane) $-\mathrm{H}_{\mathrm{b}}$ (Benzene).

for several ratios of benzene to cyclohexane at a constant concentration of MMA ([MMA], $\left.9.0 \times 10^{-2} \mathrm{moll}^{-1}\right)$, since cyclohexane is considered an inert solvent. The stability constant $(K)$ was estimated by using the following equation. ${ }^{11}$

$$
\frac{1}{\Delta}=\frac{1}{K \cdot \Delta_{0} \cdot[\mathrm{D}]_{0}}+\frac{1}{\Delta_{0}}
$$

where $\Delta$ is the observed shift for the trans olefinic proton in the system relative to that in cyclohexane, $\Delta_{0}$ represents the shift of the pure interacting species relative to that in cyclohexane, and $[D]_{0}$ is the concentration of benzene. This result is shown in 


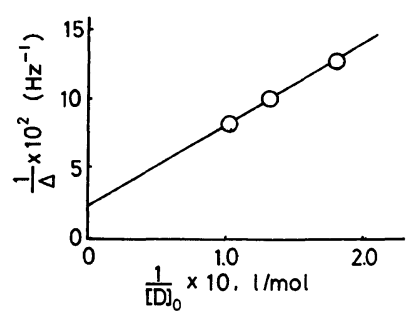

Figure 7. Plot of $1 / \Delta$ against $1 /[D]_{0}$ for the complex of MMA with benzene, cyclohexane being used as the internal reference.

Figure 7, indicating $K=0.061 \mathrm{~mol}^{-1}$. In addition, $\Delta H=0 \mathrm{kcal} \mathrm{mol}^{-1}$ was found from the temperature dependence of $K$, suggesting that the interaction between monomer and solvent did not influence the $k_{\mathrm{p}}$ values.

\section{Molecular-Orbital Calculation}

In order to check the possibility of the complex formation of the propagating radical with solvent molecules, we calculated the delocalization stabilization $(\Delta E)$ for the complex formation by Fukui's method $^{12,13}$ which was successfully used for the silver complex. The parameters for simple LCAO MO calculation are shown in Table VII. ${ }^{14,15}$ The interaction between the highest occupied molecular orbital (HOMO) and the lowest unoccupied molecular orbital (LUMO) of a donor and an acceptor was taken into account in the calculation. Since the location of the radical on the center of the aromatic ring of the solvents nullifies the HO-LU overlapping because of the symmetry of the coefficients of atomic orbital in frontier orbitals, the radical was assumed to lie above one of the $\mathrm{C}=\mathrm{C}$ bonds. The delocalization stabilization was calculated by the following formula. ${ }^{13}$

$$
\begin{aligned}
-\Delta E= & \frac{\left(C_{\mathrm{r}}^{\mathrm{LU}}+C_{\mathrm{s}}^{\mathrm{LU}}\right)^{2}\left(d_{\mathrm{N}}^{\mathrm{SO}}\right)^{2}}{\varepsilon_{\mathrm{N}}-\varepsilon_{\mathrm{LU}}} \gamma^{2} \beta^{2} \\
& +\frac{\left(C_{\mathrm{r}}^{\mathrm{HO}}+C_{\mathrm{s}}^{\mathrm{HO}}\right)^{2}\left(d_{\mathrm{N}}^{\mathrm{SO}}\right)^{2}}{\varepsilon_{\mathrm{HO}}-\varepsilon_{\mathrm{N}}} \gamma^{2} \beta^{2}
\end{aligned}
$$

where $\varepsilon_{\mathrm{HO}}$ and $\varepsilon_{\mathrm{LU}}$ are the energies of HOMO and LUMO of the solvent, $\varepsilon_{\mathrm{N}}$ is the energy of the nonbonding molecular orbital of the propagating radical $\left(\varepsilon_{\mathrm{N}}=\alpha+0.162 \beta\right)$, and $\gamma \beta$ is the resonance integral between the radical and the $r$ th and $s$ th atoms of the aromatic molecule. Notation $C_{\mathrm{r}}^{\mathrm{HO}}$ and
Table VII. $k_{\mathrm{p}}$ Value and delocalization

\begin{tabular}{|c|c|c|}
\hline \multirow{2}{*}{ Solvents } & $k_{\mathrm{p}} \times 10^{-2}$ & \multirow{2}{*}{$\Delta E,-\gamma^{2}, \beta$} \\
\hline & $1 \mathrm{~mol}^{-1} \mathrm{~s}^{-1}$ & \\
\hline \multirow{5}{*}{$\begin{array}{l}\text { (O) }-\mathrm{OCH}_{3} \\
\text { (O) } \\
\text { (O) }-\mathrm{F} \\
\text { (O) }-\mathrm{Cl} \\
\text { (O) }-\mathrm{CN}\end{array}$} & 5.06 & 0.732 \\
\hline & 4.50 & 1.048 \\
\hline & 4.48 & 1.040 \\
\hline & 4.98 & 0.866 \\
\hline & 6.14 & 0.507 \\
\hline
\end{tabular}
stabilization $^{\mathbf{a}}$

a The same parameters for simple LCAO MO calculation as reference 2 .

$C_{\mathrm{s}}^{\mathrm{HO}}$, and $C_{\mathrm{r}}^{\mathrm{LU}}$ and $C_{\mathrm{s}}^{\mathrm{LU}}$ are the coefficients of the $r$ th and sth carbon atomic orbitals in HOMO and LUMO of the solvent in which the $r$ th and $s$ th carbon atoms are adjacent to each other. Notation $d_{\mathrm{N}}^{\text {SO }}$ is the coefficient of the carbon atomic orbital of the propagating radical in the nonbonding molecular orbital.

The first term indicates stabilization resulting from the electron donation of the propagating radical to the LUMO $\pi$-orbital of the solvent and the second term, that from the electron donation of the $\pi$ electron of the solvent to the nonbonding orbital of the radical. Since the radical of MMA was found to be electron-poor, ${ }^{16}$ the radical of MMA is likely to beome an electron acceptor rather than a donor to aromatic rings. According to our theory, the complex formation generally takes place in a way such that the overlap of HOMO of the donor and LUMO of the acceptor becomes maximum. ${ }^{12,14,17,18}$ Accordingly, the complex formation is considered to occur at site such that the second term is maximum and thus the absolute value of the sum of coefficient of adjacent atomic

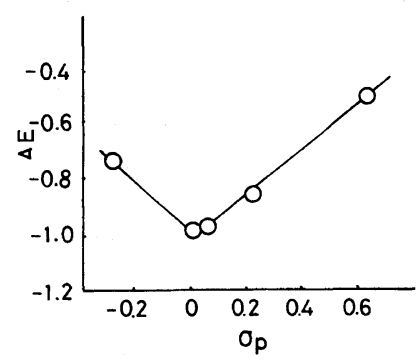

Figure 8. Correlation between delocalization stabilization and Hammett's $\sigma_{\mathrm{p}}$ of solvents. 


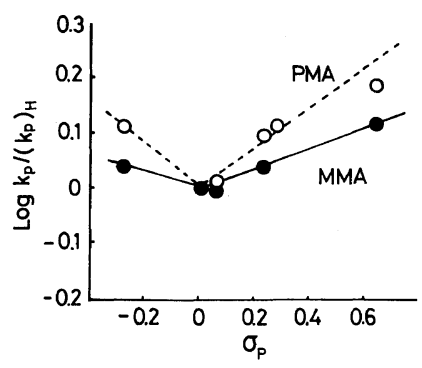

Figure 9. Correlation of $k_{\mathrm{p}}$ values for methyl methacrylate and phenyl methacrylate with Hammett's $\sigma_{\mathrm{p}}$ of solvents: -- $\mathrm{O}_{--}$, phenyl methacrylate; - - methyl methacrylate; $\left(k_{\mathrm{p}}\right)_{\mathrm{H}}$, propagating-rate constant in benzene.

orbitals of HOMO of solvent is largest, as shown in $\mathrm{Ag}^{+}$-aromatic compounds. ${ }^{13}$ The results of the calculation for the above-mentioned location are shown in Table VII and Figure 8. Variation in these values with solvent is almost consistent with the experimental results in Figure 9.

\section{DISCUSSION}

Since the rate of initiation seems to be virtually independent of the solvents used, the influence of the solvent to rate of initiation is too small to be taken into account. (Table I)

The largest $k_{\mathrm{p}}$ value is 1.4 times as large as the smallest one as shown in Table II. The solvent effect has the same trend as Bamford's result although the former is somewhat larger than the latter. ${ }^{4,5}$ The difference in the $k_{\mathrm{p}}$ values is beyond the experimental error, indicating that there is indeed solvent participation in the propagating process. Although the solvent effect on $k_{\mathrm{p}}$ for MMA is a little smaller than that observed for PMA, the trend of the solvent effect is quite similar in both system. (Figure 9)

The solvent effect on $k_{\mathrm{p}}$ must be discussed in terms of the following five points. 1. Change in the monomer reactivity by the interaction of the monomer with solvents. 2. Polarity and the polarizability of the medium. 3. Chain-transfer reaction with solvents. 4. Selective solvation of monomer with the polymer. 5. Reversible complex formation of the propagating radical with the aromatic ring of the solvent.

First, the solvent effect on $k_{\mathrm{p}}$ may be explained by the change of the reactivity of the monomer brought
Table VIII. The relation between the $k_{\mathrm{p}}$ value and the number-average degree of polymerization

\begin{tabular}{lccc}
\hline Solvents & $k_{\mathrm{p}}$ & $P_{n}{ }^{\mathrm{a}}$ & $P_{n}{ }^{\mathrm{b}}$ \\
\hline (O)-OCH & 506 & 1878 & 1933 \\
& 450 & 1406 & 1582 \\
& $-\mathrm{H}$ & 1359 & 1447 \\
$-\mathrm{F}$ & 448 & 1563 & 1741 \\
& 498 & 2167 & 2216 \\
\hline
\end{tabular}

${ }^{a}$ From [ $\left.\eta\right]$, using the relation shown by Bamford et al. ${ }^{4}$

b From kinetic chain length.

on by solvation, because the NMR study shows that there is an interaction between the monomer and solvents. However, since the enthalpy of the interaction is negligibly small and the change of the interaction with solvents indicates the same pattern as that of vinyl acetate whose $k_{\mathrm{p}}$ values change oppositely with solvent, ${ }^{19}$ solvation of the monomer is ruled out. (Table V)

Second, if these solvent effects result mainly from the polar participation of solvent in the transition state of the propagation reaction, variation in $k_{\mathrm{p}}$ with solvents should be correlated with the polarity or the polarizability of the solvent. ${ }^{20}$ No correlation could be as found between $k_{\mathrm{p}}$ and $1 / \varepsilon$ or $(\varepsilon-1) /(2 \varepsilon+1)$, where $\varepsilon$ is the dielectric constant of the solvent. Accordingly, the direct polar participation of solvent in $k_{\mathrm{p}}$ is also ruled out.

Third, rate retardation through chain transfer to the solvents is considered, because the solvent effect on $k_{\mathrm{p}}$ might possibly be caused by the difference in chain transfer to the solvent and/or the reinitiation rates by the resulting solvent radicals. However, the chain-transfer reaction to aromatic solvents used has been reported too small to warrant consideration. ${ }^{4}$ If so, the observed number-average degree of polymerization will be almost in accordance with that calculated from the kinetic chain length $\left(v_{n}\right)$, using the following relation:

$$
P_{n}=\frac{2(1+y)}{2+y} v_{n}
$$

where $y$ is the ratio of combination to disproportionation, taking $y=0.47 .^{21}$ This relation is shown in Table VIII, indicating that the transfer reaction to solvent and/or reinitiation by the resulting solvent radical is not important for the solvent effect. 
Furthermore, the fact that $k_{\mathrm{p}}$ in deuterated benzene is nearly the same as that in benzene permits the chain-transfer reaction to be neglected in the polymerization. (Table II)

Fourth, the selective solvation of the polymer with the monomer or solvent was consideration as a cause of the solvent effect. The observed $k_{\mathrm{p}}$ value is likely to be smaller in solvent which has larger solvation to the polymer, because the concentration of the monomer near the propagating polymer radical becomes smaller in the solvent. The selective solvation of the polymer to solvents or monomer was estimated by the difference in the solubility parameter between the polymer and solvent, the change of the difference in solvents being not consistent with that of the $k_{\mathrm{p}}$ value. ${ }^{22}$ In addition, the fact that solvent effect of $k_{\mathrm{p}}$ value for vinyl acetate (VAc), ${ }^{19}$ whose polymer has a solubility parameter similar to poly(MMA), ${ }^{22}$ is opposite to that for MMA indicates that the selective solvation with the polymer is not an important factor in the solvent effect.

Fifth, the reversible formation of a chargetransfer complex between the propagating radical and aromatic solvents must be considered. ${ }^{1,4,5} \mathrm{We}$ have pointed out the validity of the concept that the solvent effect on $k_{\mathrm{p}}$ for PMA was caused mainly by the radical complex. ${ }^{1,2}$ Since MMA has a propagating radical similar to PMA, the same solvent effect will be observed in the rate constant. This expectation is the case. The relationship of $k_{\mathrm{p}}$ to Hammett $\sigma_{\mathrm{p}}$ values of substituents shows that the $k_{\mathrm{p}}$ values shift to large values by either donor or acceptor substituents (Figure 9). Since similar effects were found in some radical reactions in which aromatic rings directly or indirectly participate,,$^{23-27}$ the variation in $k_{\mathrm{p}}$ with $\sigma_{\mathrm{p}}$ also indicates that participation of the $\pi$-system of the solvent in the reactivity of the propagating radical must be taken into account. Accordingly, the radical complex between the propagating radical and solvents seems to be attractive for elucidating the solvent effect. The MO calculation which considers both the energy level and local electron density of frontier orbitals supports the possibility that variation in $k_{\mathrm{p}}$ with solvents is due to the complex formations with solvents. (Table VII and Figure 8)

A solvent effect for MMA smaller than that for PMA might possibly be due to the difference in complex stabilization, since the PMA radical was found in the copolymerization data to be more electropositive than the MMA radical and thus is considered to have more electron-accepting ability. ${ }^{28}$

The behavior of the propagating radical of PMA in aromatic solvents is assumed as follows.

$$
\begin{aligned}
& \mathrm{P}_{n} \cdot+\mathrm{S} \stackrel{K_{\mathrm{s}}}{\rightleftharpoons} \mathrm{P}_{n} \cdot \mathrm{S} \\
& \mathrm{P}_{n} \cdot+\mathrm{M} \stackrel{K_{\mathrm{m}}}{\rightleftharpoons} \mathrm{P}_{n} \cdot \mathrm{M} \\
& \mathrm{P}_{n} \cdot \mathrm{M} \stackrel{k_{\mathrm{po}}}{\rightleftharpoons} \mathrm{P}_{n+1} .
\end{aligned}
$$

where $K_{\mathrm{s}}$ and $K_{\mathrm{m}}$ are association constants for the above equilibria and $k_{\mathrm{po}}$ is a true propagation-rate constant independent of the polymerization medium. The observed propagation-rate constant $\left(k_{\mathrm{p}}\right)$ is represented by eq 2 on the assumption that the propagating radical complex with the aromatic ring is in a dormant state,

$$
k_{\mathrm{p}}=\frac{k_{\mathrm{po}}}{1+K_{\mathrm{m}}[\mathrm{M}]+K_{\mathrm{s}}[\mathrm{S}]}
$$

Equation 2 may be represented by the solvent concentration as shown in eq 3 .

$$
k_{\mathrm{p}}=\frac{k_{\mathrm{po}}}{1+K_{\mathrm{m}}\left(\frac{1000 d_{\mathrm{m}}}{M_{\mathrm{m}}}\right)+\left(K_{\mathrm{s}}-K_{\mathrm{m}} \frac{d_{\mathrm{m}} M_{\mathrm{s}}}{d_{\mathrm{s}} M_{\mathrm{m}}}\right)[\mathrm{S}]}
$$

where $d_{\mathrm{m}}$ and $d_{\mathrm{s}}$ are monomer and solvent densities and $M_{\mathrm{m}}$ and $M_{\mathrm{s}}$ are their molecular weights, respectively. Therefore, if this mechanism is correct and $K_{\mathrm{s}}$ is not equal to $K_{\mathrm{m}} d_{\mathrm{m}} M_{\mathrm{s}} / d_{\mathrm{s}} M_{\mathrm{m}}$, then the observed $k_{\mathrm{p}}$ value will depend on the concentration of the solvent. The fact that the $k_{\mathrm{p}}$ value decreased with an increase in the solvent concentration seems to support this mechanism. The activation energies of $k_{\mathrm{p}}$ and $k_{\mathrm{t}}$ seem almost the same as those reported in the bulk polymerization $\left(E_{\mathrm{p}}=4.4 \mathrm{kcal} \mathrm{mol}^{-1}\right.$ and $\left.E_{\mathrm{t}}=0.0 \mathrm{kcal} \mathrm{mol}^{-1}\right),{ }^{29}$ indicating that the temperature dependence of these values is not influenced by the complex formation of propagating radicals.

When it is assumed that the monomer complexation is neglected the observed $k_{\mathrm{p}}$ is represented by eq 4 .

$$
k_{\mathrm{p}}=\frac{k_{\mathrm{po}}}{1+K_{\mathrm{s}}[\mathrm{S}]}
$$

From the plot of $1 / k_{\mathrm{p}}$ against [S], $K_{\mathrm{s}}$ was estimated 


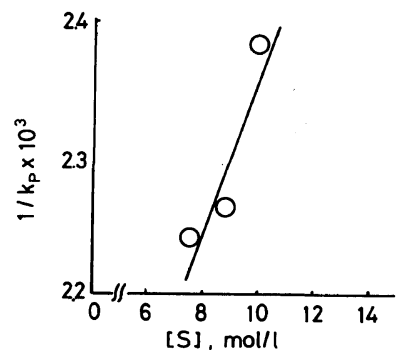

Figure 10. Plot of the reciprocal of the $k_{\mathrm{p}}$ value against solvent concentration; solvent, benzene.

to be $3.1 \times 10^{-2} 1 \mathrm{~mol}^{-1}$ (Figure 10), indicating that the fraction of the complexed radical is about one fifth of the propagating radical at $[\mathrm{S}]=8.8 \mathrm{moll}^{-1}$. Since radical complexation with the monomer might not be neglected, the above $K_{\mathrm{s}}$ values may still have some ambiguity.

The influence of the complex formation on the termination-rate constant also should be taken into account. The following termination processes are considered in the polymerization.

$$
\begin{aligned}
& \mathrm{R} \cdot+\mathrm{S} \stackrel{K_{\mathrm{s}}}{\rightleftharpoons} \mathrm{R} \cdot \mathrm{S} \\
& \mathrm{R} \cdot \quad+\mathrm{R} \cdot \stackrel{k_{\mathrm{tl}}}{\longrightarrow} \mathrm{R}-\mathrm{R} \\
& \mathrm{R} \cdot \mathrm{S}+\mathrm{R} \cdot \stackrel{k_{\mathrm{t} 2}}{\longrightarrow} \mathrm{R}-\mathrm{R}+\mathrm{S} \\
& \mathrm{R} \cdot \mathrm{S}+\mathrm{R} \cdot \mathrm{S} \stackrel{k_{\mathrm{t} 3}}{\longrightarrow} \mathrm{R}-\mathrm{R}+2 \mathrm{~S}
\end{aligned}
$$

When the fraction of the complexed radical is $\alpha$, the observed termination-rate constant $\left(k_{\mathrm{t}}\right)$ is shown in the following formula.

$$
k_{\mathrm{t}}=k_{\mathrm{t} 1}(1-\alpha)^{2}+2 k_{\mathrm{t} 2} \alpha(1-\alpha)+k_{\mathrm{t} 3} \alpha^{2}
$$

Since the complexed radical is considered to be less reactive, the rate constants decrease in the order: $k_{\mathrm{t} 1}>k_{\mathrm{t} 2}>k_{\mathrm{t} 3}$. Therefore, when $\alpha$ is considerably smaller than $1, k_{\mathrm{t}}$ is likely to be affected mainly by $k_{\mathrm{t}}$, being linearly correlated with the reciprocal viscosity. This view reasonably explains the influence of solvents on $k_{\mathrm{t}}$ for MMA in the present polymerization systems whose $K_{\mathrm{s}}$ values are considered to be smaller than $3.1 \times 10^{-2}$. When $\alpha$ becomes larger, a deviation from the linear correlation is presumed. This was shown to be the case in the polymerizations of vinyl acetate, whose $K_{\mathrm{s}}$ values were much larger. ${ }^{19}$

\section{REFERENCES}

1. M. Kamachi, J. Satoh, D. J. Liaw, and S. Nozakura, Macromolecules, 10, 501 (1977).

2. M. Kamachi, D. J. Liaw, and S. Nozakura, Polym. J., 9, 307 (1977).

3. M. Kamachi, J. Satoh, and S. Nozakura, J. Polym. Sci., Polym. Chem., Ed., 16, 1789 (1978).

4. C. H. Bamford and S. Brumby, Makromol. Chem., 105, 122 (1967).

5. C. H. Bamford, "Molecular Behaviour and the Development of Polymeric Materials," A. Ledwith and A. M. North, Ed., Chapman and Hall, London, 1975, pp 51-87.

6. G. M. Burnett, G. G. Cameron, and M. M. Zafar, Eur. Polym. J., 6, 823 (1970).

7. T. Yamamoto, S. Yamamoto, T. Yamamoto, and M. Hirota, Nippon Kagaku Kaishi, 618 (1980).

8. R. Korus and K. F. O'Driscoll, "Polymer Handbook" 2nd ed, J. Brandrup and E. H. Immergut, Eds., Wiley, New York N.Y., 1975, Chapter II, p 45.

9. P. E. Allen and B. O. Bateup, Eur. Polym. J., 9, 1283 (1973).

10. M. Kamachi, D. J. Liaw, and S. Nozakura, Polym. Prepr., Jpn., 27, 708 (1978).

11. R. Foster, "Organic Charge Transfer Complexes," Academic Press, London-New York, N.Y., 1969, p 142.

12. K. Fukui, "Theory of Orientation and Stereoselection," Springer-Verlag, Berlin, Germany, 1975, pp 40-85.

13. K. Fukui, A. Imamura, T. Yonezawa, and C. Nagata, Bull. Chem. Soc., Jpn., 34, 1076 (1961).

14. K. F. O'Driscoll and T. Yonezawa, Rev. Macromol. Chem., 1, 1 (1966).

15. N. Kawabata, T. Tsuruta, and J. Furukawa, Makromol. Chem., 51, 80 (1961).

16. K. Tsuda, S. Kobayashi, and T. Otsu, J. Polym. Sci., $A-1,6,41$ (1968).

17. R. S. Mulliken, Rec. Trav. Chim., 75, 845 (1956).

18. R. S. Mulliken and W. B. Person, "Molecular Complexes," Wiley-Interscience, New York, N.Y., 1969.

19. M. Kamachi, D. J. Liaw, and S. Nozakura, Polym. J., 12, 921 (1979).

20. E. A. Moelwyn-Hughes, "Chemical Statics and Kinetics of Solution," Academic Press, London-New York N.Y., 1971.

21. J. C. Bevington, H. W. Melville, and R. P. Taylor, $J$. Polym. Sci., 12, 449 (1954).

22. H. Burrel, "Polymer Handbook," 2nd ed, J. Brandrup and E. H. Immergut, Eds., Wiley, New York, N.Y., 1975, Chapter IV, pp 341-353.

23. T. Yamamoto and T. Otsu, Bull. Chem. Soc., Jpn., 40, 2449 (1967). 
M. KamaChI, D. J. Liaw, and S. NozaKura

24. T. Yamamoto and T. Otsu, J. Polym. Soc., A-1, 6, 49 (1968).

25. M. Imoto, M. Kinoshita, and M. Nishigaki, Makromol. Chem., 86, 217 (1965).

26. M. Imoto, M. Kinoshita, and M. Nishigaki, Makromol. Chem., 94, 238 (1966).

27. T. Otsu, "Progress in Polymer Science," Vol. I. M.
Imoto and S. Onogi Ed., Kodansha, Tokyo, 1971, pp 39- 55.

28. M. Kamachi, D. J. Liaw, and S. Nozakura, Polym. Prepr., Jpn., 26, 107 (1977).

29. M. H. Mackay and H. W. Melville, Trans. Faraday Soc., 45, 323 (1949). 